\title{
Educational Expansion and Interest in Politics in Temporal and Cross-cultural Perspective: A Comparison of West Germany and Switzerland
}

\author{
Andreas Hadjar and Florian Schlapbach
}

Interest in politics is a prerequisite for political participation and political engagement. The promotion of political engagement and the education of citizens to become politically mature were basic concerns of educational reforms in the 1960s. This article examines whether educational expansion since then has had an impact on citizens' political interest. The effects of education, age, period, and cohort on political interest are analysed simultaneously. A cross-cultural perspective is included by comparing these effects in Switzerland, a direct democracy that provides its people with extensive opportunities to participate, and West Germany, a representative democracy with less such opportunities. The data base consists of cumulated data sets (ALLBUS, UNIVOX). Results show that there is a robust effect of education: the more educated are more politically interested. The younger generation is not, as is often suggested, more distant from politics. Taking into account their higher educational level, these younger cohorts show the same level of political interest as the older cohorts did at the same age.

\section{Introduction}

This article links two key conditions of democracy: education and interest in politics. To assess whether educational expansion over recent decades has led to an increase in political interest, two different political systems-West Germany as a representative democracy and Switzerland as a direct democracy-are compared. The focus on only two societies follows Ebbinghaus' (2005) 'less is more' strategy, which aims at a more detailed description of political and institutional context and includes a deliberate case selection. Switzerland and West Germany have been chosen as they differ in their modes of institutionalized political participation but have similar highly stratified education systems.

The promotion of political interest and political participation has been a major aim of educational reform in the 1960s in European countries. In Switzerland, this aim was not explicit as the main issues driving educational reform were related to deficits in the workforce (Rieger, 2001). In West Germany, some sought to change the educational system in order to compete more effectively with communist states, but social democratic and liberal thinkers like sociologist Ralph Dahrendorf (1965) saw improved education as a matter of civil liberties and as a requirement for the development and maintenance of a democratic society 
(Müller, 1998, p. 85). For Dahrendorf, education should help people understand the political system, articulate their rights, and participate actively in political processes and decisions.

An important element of such outcomes is political interest, which may be defined as the degree to which 'politics arouses citizen's curiosity' (van Deth, 1990, p. 278). Political interest is a conative component of the attitudinal system, and thus is closely linked to political behaviour and political participation (Breckler, 1984). A lack of political interest reduces people's willingness to participate, as reflected for example in low voter turnout (Lazarsfeld et al., 1948) and in a general lower probability of conventional and unconventional political activities (Hadjar and Becker, 2006a). These links between interest and behaviour mean that our analysis of political interest has implications for the understanding of political behaviour. Political interest also contributes to the stability of the political system (Easton, 1975).

Our main research question is whether the expectation, at least as expressed in West Germany in the 1960s, that an increase in university-bound and tertiary education would raise political interest has been fulfilled by the educational expansion that occurred since then. Following a theoretical section on the relationship between education and political interest and a short account of the German and Swiss political systems, the paper presents some descriptive results on period, cohort, and educational differences in political interest. It then turns to multivariate analysis; here age, period, and cohort effects are modelled simultaneously. The analysis focuses on mechanisms and links rather than on absolute levels of political interest or educational attainment, as these variables were measured differently in the data sets used and cannot readily be adapted to make them comparable.

\section{Educational Expansion and Interest in Politics}

To explore change in political interest over recent decades and how it was affected by educational expansion, the article first pursues a static individual level analysis and then develops a dynamic perspective that considers temporal hypotheses.

\section{Education and Interest in Politics on the Individual Level}

Higher education goes hand in hand with improved information processing and problem-solving skills and higher behavioural competences. According to sociopsychological studies (Lind, 1985, 1988), it also contributes to moral development and responsibility. These outcomes result in improved participation and expanded opportunities in several realms of private and public life (Baumert, 1991, p. 347). Regarding politics, improved cognitive skills enhance people's political competences (Inglehart, 1977; Dalton, 1984). The better educated-who are also more likely to attain higher social status-have easier access to politics (cf. Verba and Nie, 1972), as they have greater competence in recognizing, understanding, and reflecting on political issues. They also have a greater sense of 'internal political efficacy' (Vetter, 2000; Becker, 2004), that is, a greater confidence in their own ability to deal with and participate in political processes. They are more likely to expect success in political reflection, political behaviour, and in achieving desired outcomes (cf. Becker, 2004). Better education also reduces the cost of political interest and political participation, since improved cognitive skills reduce the cost of information search and reflection on political questions (Hadjar and Becker, 2006a, b). These costs are further reduced through the embeddedness of the more highly educated in communication networks where political issues are often a central theme. In sum, the first hypothesis is that higher education raises internal political efficacy and actual political competence and thus makes the better educated more interested in politics.

Hypothesis 1: Political interest increases with increasing educational level.

This leads to the question of how educational expansion affects political interest and here a longitudinal perspective is required.

\section{Cognitive Mobilization and Compositional Change in Educational Expansion}

To examine the link between educational expansion and change in interest in politics in West Germany and Switzerland, we will focus on two major aspects of educational expansion-cognitive mobilization and change in the composition of educational groups (i.e. heterogenization of the better educated and homogenization of the less educated). Cognitive mobilization is a desired consequence of educational reforms. Heterogenization, while perhaps reducing educational inequalities, may have had the unwanted effect of lowering standards in intermediate and universitybound educational institutions. 
Cognitive mobilization, as theorized by Inglehart (1990) and Dalton (1984), is a direct and central consequence of educational expansion. It may be regarded as an element of long-run collective social change (Baumert, 1991, p. 347; Baumert et al., 2003) and as an influence on how individuals relate to the macro context. A better educated population implies better access to politics and higher internal political efficacy and therefore should give rise to an increase in interest in politics. Such outcomes are not only caused by the educational expansion but also by the expansion of the mass media and the development of homogeneous socialization environments (Klingemann and Fuchs, 1995).

An expected consequence of educational expansion that was often less than fully realized (Becker, 2003) was a change in the composition of educational categories. As intermediate and university-bound school tracks were opened up to all social classes-although in Germany and Switzerland social origin and educational level remained correlated-there was an influx of formerly excluded social classes (e.g. farmers, manual workers). This influx was relatively greater than that of the advantaged classes, although not to the expected and politically desired degree. Nevertheless, the link between social origin and educational attainment weakened (Becker, 2003). ${ }^{1}$ Due to this heterogenization, the standards of the intermediate and university-bound educational institutions may have decreased. This fear was first expressed by Schelsky (1956), who argued that expanded access to higher education would increase diversity and dilute the resources and potential of the better educated. Following Baumert (1991), the distinctiveness in skills, competences, orientations, and behavioural patterns of those with post-compulsory schooling would be expected to have declined during the course of the educational expansion. Although heterogenization is a key feature of this process, it may merely have moderated rather than reversed the effect of cognitive mobilization on skills and competences (cf. Müller, 1998). A possible decrease in standards in intermediate and university-bound educational institutions may have been accompanied by a greater homogenization in lower level institutions, which also decreased standards at this educational level, as only people from low social backgrounds remain in this 'residual category' (cf. Solga, 2002).

Considering interest in politics, one would expect a slight tendency for the interest level of the better educated to converge towards that of the less educated. The main reason for this is the greater participation in intermediate and university-bound school tracks among those from the lower classes whose class habitus
(Bourdieu, 1984) makes them rather distant from politics. This raises the proportion of the politically less interested among the better educated. At the same time, the least educated may retain their lower political interest due to the process of homogenization.

In sum, it may be stated that the educational expansion has led to a 'political sophistication of Western mass publics' (Dalton, 1984, p. 265), characterized by an increase in 'internal political efficacy' and a decrease in costs to deal with politics. Therefore, it may be expected that the rise in participation in higher school tracks goes along with a rising political interest in the population. This process may be slowed down by the change in the composition of the student population regarding social origin - an increasing heterogenization of the group with intermediate and university-bound educational certificates and an increasing homogenization of the group of the less educated people. The level in interest in politics of the more highly educated people converges to the interest level of the lowest educational group.

\section{Educational Expansion and Political Interest in Temporal Perspective: Cohort, Period, and Age Effects}

Assumptions on temporal trends and postulations of linear temporal developments must be handled very carefully and critically, as such developments and changes may be compositions of different temporal effects. The simultaneous consideration of these effects-age, period, and cohort-is necessary to recognize the actual temporal mechanisms behind the change.

The pattern of cohort differences should follow the course of the educational expansion in West Germany and Switzerland. A strong increase in interest in politics over cohort succession may be expected for West Germany, whereas for Switzerland a rather moderate rise appears to be plausible, since already in the 1960s educational scientists stated that Switzerland 'is well endowed with schools' (Panchaud, 1967, p. 374). Although a causal relation between educational expansion and a rise in political interest is the core assumption of this article, formative socialization experiences of the cohorts-which are not directly, but maybe indirectly related to education-are possibly another force behind the change. Similar to the concept of political generations (Mannheim, 1928; Metje, 1994), we define a cohort as a generation that is characterized by a certain educational level, by shared socialization experiences and therefore has a common general world view-although there may be differences. This world view may be assumed as relatively stable 
over time-as theorized in the socialization thesis of Inglehart (1977).

For the analyses, we use cohort bundles characterized by their specific educational level. In both samples, the birth cohorts 1954-1971 benefited most from the educational expansion and therefore may have a higher level of cognitive mobilization. Additionally, also arguments regarding political mobilization may be considered. In the relatively stable democratic system of Switzerland, the rise in political interest over the birth cohorts may not be as strong as in West Germany. However, there may be also a rise in political interest, as there have been events in the 1968s and the 1980s, which may have supported a political sensitization.

According to the theoretical exploration of the link between educational level and interest in politics, the cohort effect represents partly a 'cognitive mobilisation' (Dalton, 1984; cf. Inglehart, 1977; Baumert et al., 2003). In regard to the cognitive mobilization as a main consequence of the educational expansion, younger cohorts-which were educated from the 1960s onwards-may be expected to have a higher educational level and therefore a greater interest in political issues.

Hypothesis 2a: Younger cohorts have a stronger political interest.

Taking into account the argument of a changing composition of the educational groups-in particular regarding heterogenization and homogenization-in both West Germany and Switzerland, the gap between more highly educated people and less educated people in political interest may decrease. Whereas intermediate and highest educational groups may be expected to lose some interest in politics compared to the group with low educational degrees, the lowest educational group may keep its negative distinction and maintain its low level of interest in politics. This might be due to the heterogenization of intermediate and universitybound education, as well as due to the homogenization of low level schools.

Hypothesis 2b: The distinction of the more highly educated people in their higher political interest level decreases over time. The lowest educational group maintains its lower interest level.

Following empirical evidence, period effects seem to influence the societal level of political interest. Period effects are related to societal events, political developments, and societal conditions both on the structural and ideological level that affect all birth cohorts. Nevertheless, there will be cohort-specific variations in the perception of these context conditions and in how cohort members deal with such period-specific circumstances. Strong period effects are likely to occur in the environment of elections and in times of strong societal problems (e.g. unemployment, environmental crisis, or recession). This fits with the assumption of Klages (1984) who interprets political interest in terms of dissatisfaction with the political system and governmental policies. An increasing perception of problems leads to a decrease of 'political trust' in the stateresulting in a higher political interest level. Looking at the times of survey between 1992 and 2004, political interest in West Germany should have increased towards the beginning of 1990s as the unemployment rate increased and many people lost their trust in the conservative government of Chancellor Kohl. Another peak may be expected for 2002, since then people became more and more dissatisfied with the Schröder government and its social reform project ('Agenda 2010'). In Switzerland, at the same time period a large discussion about the UN and EU integrationculminating around the referendum on the UN integration in 2001-may have politically mobilized the Swiss population. These political debates and the perception of social problems may be reflected in a rise in political interest at the beginning of the 21st century.

As period effects depend on various issues, it does not seem appropriate to postulate a linear period effect.

Hypothesis 3: Effects of education and cohorts are superposed by period effects. Peaks in political interest may be stated for the beginning of the 21st century in both West Germany and Switzerland.

The postulated cohort and period effects do not stand alone, but are superposed by an age effect-as political orientations and behaviour develop and increase during the lifelong socialization process (HoffmannLange, 1993). Although there may be a core phase of political socialization during late adolescence, knowledge, and reflection competences may increase over the life cycle. Evidence suggests that children already identify with political issues, but a substantial understanding of political processes will not appear before the age of 15 (Hess and Torney, 1970). From young adulthood to middle age, political interest as well as political participation increase. This process reflects a 'gradual learning', i.e. a continuous political socialization through experiences in the sense of Verba and 
Nie (1972). According to the disengagement thesis of Cumming and Henry (1961), the process of political socialization and political learning stagnates after the age of 60, as people retire from work life and are less involved into politics. Whereas evidence suggests that highest voter turnout and highest political interest is to be expected for the fifties and that there is a pronounced increase up to then, the assumed decline of political interest during the sixties and seventies did not find proof in empirical analyses (Glenn and Grimes, 1968). On the contrary, it may be assumed that at older ages 'attention to politics becomes a functional substitute for the activities and concerns that absorbed so much time and energy earlier' (Glenn and Grimes, 1968, p. 573). A declining political interest at older ages also does not seem very plausible considering public discourses on pensions and health care. Although empirical findings on the change of political interest at older ages are ambivalent, at least the linearity of the age effect is to put in doubt according to the cited assumptions and evidences. Therefore, we assume no decline, but an increase stagnation regarding political interest after middle age.

Hypothesis 4: Political interest increases with age. This increase stagnates after middle age.

\section{The Political Systems in West Germany and Switzerland}

Although West Germany and Switzerland are cultural neighbours, many differences can be identified. Before doing the analyses, descriptions of the political systems and institutions and a brief summary about the educational expansion in both countries are provided for a better interpretation of the results.

Regarding the political system, differences in the system itself as well as in the amount, respectively, the strength of system interruptions can be recognized. In the last century, when most of the modern political systems emerged, the West Germans experienced some interruptions regarding their political and economic system. The current political system is characterized by few opportunities of the population to directly influence the political decision-making process: the people are asked to elect their representatives for the 'Bundestag' (Federal Diet) every 4 and the 'Landtag' (Diet of State) every $4-5$ years. New bills are resolved and passed by the Bundestag immediately-without the opportunity of the population to dismiss or approve them. Apart from some limited regional or local participation occasions, the German constitution provides no general opportunities for initiatives or referendums.
Switzerland never experienced political struggles like Germany did. The Swiss Confederation was virtually never involved in any wars. The political and economic systems remained relatively stable. Every large party is represented in the Swiss government according to the so called concordance principle. Various institutionalized opportunities allow a direct participation of the population in the political process; for instance regular votes on new or revised bills and the possibility to initiate referendums and initiatives. Every year, three to four voting weekends are held. The 'Nationalrat' (National Council) and the 'Ständerat' (Council of States) are elected every 4 years. Apart from the 'Bundesrat' (Federal Council), the politicians work on a voluntarily base with compensation and most of them pursue a profession beside their parliamentary function.

Due to the various opportunities to participate in the political process-accompanied by a constant activation of political thinking, e.g. booklets sent to the homes for every voting weekend and a distinct press coverage on the current topics-political interest in Switzerland should be much higher than in West Germany with fewer participation opportunities. This may be backed by the theoretical background outlined above, as the perception of more opportunities to influence the political process should lead to a higher belief in political efficacy. But these many opportunities can at the same time weaken the political process. Some authors speak about an increasing disenchantment with politics ('Politikmüdigkeit') in Switzerland and back this by looking at voter participation rates in elections: about 48 per cent in Switzerland compared with 85.9 per cent in Germany for the period 1975 until 1993 (Freitag, 1996, p. 5).

The main aim of the West German Educational Reform in the 1960s was the promotion of political interest and political participation. Therefore, younger cohorts should be more interested in politics due to their increased educational level. The educational expansion took also place in Switzerland, even though starting at a higher base level and following a smoother course (i.e. a slighter incline). The increase in A-level graduates and tertiary graduates has been not as strong as in West Germany (Buchmann et al., 1993).

According to the above discussed aims of the educational reforms and the theoretical assumption of an education-political interest link, political interest should rise with the educational expansion. This means that as long as the expansion in Switzerland is smoother than in West Germany, political interest should increase to a larger extent over cohort succession in West Germany. Since Switzerland is characterized by a higher 
Table 1 Differences in political interest between West Germany and Switzerland

Political interest/political efficacy:

Change of political interest:

Cohort differences in political interest:

Educational differences in political interest:
West Germany $<$ Switzerland

West Germany $>$ Switzerland

West Germany $>$ Switzerland

West Germany $>$ Switzerland political efficacy and since instruments of political activation-in particular, prior to federal votes throughout the year-are directed towards all social classes here, we suppose that the gap in political interest between more highly educated and lower educated people in Switzerland is not as large as in West Germany.

Although different assumptions may be derived from this exploration, the theses in Table 1-following a perspective that focuses on the role of educationwill be part of the theoretical background.

\section{Research Design: Methods, Sample, and Instruments}

\section{A-P-C Analyses}

To analyse social change adequately and to prevent 'temporal fallacy', social change will be understood as a composition of age, period, and cohort effects and therefore analysed by using an Age-Period-Cohort (A-P-C) design-meaning a simultaneous modelling of these three temporal effects (cf. Hagenaars, 1990; Bürklin et al., 1994). A temporal fallacy refers to the drawing of wrong conclusions from findings on one or two temporal levels. For instance, value change is not just a cohort effect-as Inglehart (1990) has put it-, but may be overlaid by age and period effects. Younger cohorts prefer post-materialist values not only due to their cohort-specific socialization experiences, but also because of their younger age and period influences at the time of data gathering. Respectively, it may be assumed that the change in political interest is a composition of effects of the cohort-specific socialization and educational level, aging effects (position within the life cycle), and effects of the time of survey (political and societal events and conditions or Zeitgeist). ${ }^{2}$

A problem of A-P-C analyses is the confounding or multicollinearity problem that occurs when age, period, and cohort variables are introduced simultaneously in a regression model, as Period $=$ Age + Cohort (cf. Glenn, 2005). To prevent confounding, the common strategy to substitute one of the temporal variables is employed here. This means to include measures of the causal variables for which age, period and cohort are surrogates' (Tuma and Hannan, 1984, p. 192). Therefore, in the entire A-P-C models the metric cohort variable will be substituted by the cohort-specific heterogeneity of the school student population. Although there is a homogenization trend regarding low level education, intermediate, and university-bound educational institutions are characterized by an increasing heterogeneity of their student populations regarding social origin. The heterogeneity level is the inverse association between father's Goldthorpe class (four-class version; Breen, 2005, p. 41) and school leaving degree.

\section{Database}

The main analyses are based on two cumulated longitudinal data sets. For West Germany, ALLBUS surveys conducted between 1992 and 2004 were used. ALLBUS stands for the German General Social Survey-a biennial survey (starting in 1980) on attitudes, behaviour, and social structure in the Federal Republic of Germany. For Switzerland, a cumulated VOX data set was created from every second of the yearly surveys between 1992 and 2004 to make the data comparable to the German data basis. The VOX surveys have been carried out after each federal vote in Switzerland since 1977. It covers political issues: preferences, participation, opinions on social issues, and socio-demographic variables of Swiss citizens.

Although both data sets are comparable to some extent, there are some differences that must be taken into account-particularly regarding measures. To make both samples more comparable, the samples were reduced as well as the range of some variables. The Swiss sample does not contain non-citizens. The West German sample was therefore reduced to people who are in possession of the German citizenship. Both the Swiss and German samples were additionally reduced to control for socialization experiences, to include people with a relatively fixed general educational level and to avoid selection effects regarding very old people. People with no degree were also excluded from the analyses, as this category does not apply to the Swiss educational system-the law does not permit 
leaving school without any certificate. The samplescollected biennially between 1992 and 2004-consist of people from 21 years of age, but not older than 80 who were born between 1924 and 1971 (West Germany $N=11,965$, Switzerland $N=20,965)$.

\section{Measures}

To measure the dependent variable political interest, in Germany people were asked 'How interested in politics are you?' on a five-step scale ranging from 'not at all interested' via 'less interested', 'medium interested' and 'strongly interested' to 'very strongly interested'. In Switzerland, the question was the same, but people had to decide between four categories: 'not at all interested', 'rather less interested', 'rather strongly interested', and 'very strongly interested'. This instrument complies with the measurement of political interest 'by asking people directly how interested they are in politics' (Gabriel and van Deth, 1995, p. 395) that is popular in social science research since the 1950s. For the analyses, this variable was dichotomized to two categories: ' 0 ' stands for 'no or small interest in politics' and ' 1 ' for 'strong and very strong interest'. For West Germany the category ' 1 ' consists of people with strong and very strong interest, for Switzerland the category consists of people with very strong interest. This strategy seems to be meaningful as it also controls for the bias that results from the time of data gathering in Switzerland. The Swiss VOX surveys were all carried out close to federal votes-which makes an extended political interest plausible. Results based on this dichotomization of the variable show that in the West German sample the political interest level is higher than in Switzerland (Figures 3 and 6 below). ${ }^{3}$

Education was measured via the general school leaving degree. Due to the strong stratification of the educational systems in Germany and Switzerland, the general school-leaving certificate determines the further career to a large extent-in particular, the transition to vocational education or tertiary education and the school-to-work transition (cf. Müller and Shavit, 1998). The different educational systems and measurements in West Germany and Switzerland only allow a simplified educational variable to be included into the analyses. The general school leaving degree was collapsed into three categories: lower educational level includes people with a low degree as one receives after attending a low level secondary school, intermediate educational level refers to people who gained an intermediate school-leaving certificate. The category 'high educational level' applies to people who successfully finished a university-bound school track or received at least a full general or vocational maturity certificate (CASMIN level 2c; Brauns and Steinemann, 1999). In the West German sample, this category includes people with Abitur and Fach-Abitur, in the Swiss sample this applies to all people who attended a Maturitätsschule/Gymnasium, a teacher's school or a higher vocational or higher technical school. ${ }^{4}$

The birth cohort as one of three temporal variables will be included in various ways into the following analyses. Cohorts will be bundled up into five dummy variables that are characterized by a specific educational level and certain socialization experiences. To figure out a trend regarding the political interest over all birth cohorts, the year of birth will be included. A third way to analyse cohort effects-and a way that is necessary when modelling age, period, and cohort effects simultaneously-is to substitute the conventional cohort variable 'year of birth' by a variable that represents an important cohort characteristic (Tuma and Hannan, 1984; Glenn, 2005). Such a surrogate is the heterogeneity variable. Regarding educational expansion, cohort succession is not just characterized by a rising educational level (that is already included in the models), but by a rising heterogeneity that results from the opening up of the higher school tracks to all classes. The heterogeneity level is represented by the Cramer's V parameter for the association between social origin and the educational level. Social origin is conceptualized as the class of the father. Class is categorized by use of the Erikson-Goldthorpe-Portocarero (EGP) class schema (Erikson et al., 1979). ${ }^{5}$ As a higher value of Cramer's V indicates homogeneity, the inverse Cramer's V is used as substitute for each year of birth or cohort. For West Germany the cumulated ALLBUS data set 1992-2004 (reduced sample: German citizens in West Germany, cohorts 1924-1971, aged 21-80; $N=11,965)$ was used to calculate the Cramer's V for the association of father's EGP class and the dichotomized educational level-group 1 contains people with a higher education entrance certificate, group 0 comprises of people with lower educational levels. The birth cohort-specific heterogeneity levels for Switzerland had to be acquired from other data sources as such data was only available in the Swiss Household Panel (SHP). We had to use the first survey of the SHP (1999), since at this time the number of cases is higher compared to later surveys that were affected by panel mortality. Due to the fact, that the SHP is a panel survey, a pooling of several SHP data sets had not been meaningful, as the sample stays the same. After the reduction of the data set to Swiss citizens, born between 1924 and 1971 and aged 21-80, 
the number of cases decreased to $N=6,716$. Such a low case number is only suboptimal for the estimation of the cohort-specific heterogeneity; however, due to the lack of other Swiss data, the SHP 1999 had to be used to estimate the association between father's Goldthorpe class and the trichotomized education variable. As Figures 1 and 2 (see below) show, the heterogeneity graph has the same course like the educational expansion graph. Heterogeneity is the more appropriate cohort substitute, since it is less confounded with the cohort variable, as the educational expansion brought no strong decline in educational inequalities (Becker, 2003; Shavit et al., 2007).

The time period-that is the year of data gathering-was included as dummy variables into the model, each standing for 1 year. Age is introduced as age in years. We also test a squared age effect assuming that the political interest decreases with age and then stagnates after middle age.

Gender is introduced as a control variable for three reasons: first, empirical evidence suggests a gender gap in political participation and political interest: women are less interested in politics and participate to a lower extent. Second, women benefited most from the educational expansion; gender inequalities regarding educational opportunities declined. Third, the introduction of a gender variable into A-P-C models is meaningful, since women have a higher life expectancy-which otherwise would lead to a biased age effect (cf. Hadjar and Becker, 2007, p. 421). The dichotomous gender variable refers to the male gender represented by a ' 1 ' and a ' 0 ' for females.

\section{Results: Political Interest in Temporal Perspective}

Before analysing political interest, the courses of the educational expansion in West Germany and Switzerland are to be reconstructed. In Figures 1 and 2, cohort differences in education-the proportion of more highly educated people - and heterogeneity level regarding the five cohort bundles are shown. Cohorts are collapsed into regular cohort bundles of 10 years-the last cohort consists of 8 years of birth for methodological reasons to prevent selection effects. These figures may give some preliminary information on the course of the process of educational expansion, although proportions are not easily comparable. ${ }^{6}$

In both countries, the average educational level rises gradually. In West Germany, only 13 per cent of the members of the 1924-1933 birth cohorts are highly educated, whereas the proportion rises to 35 per cent

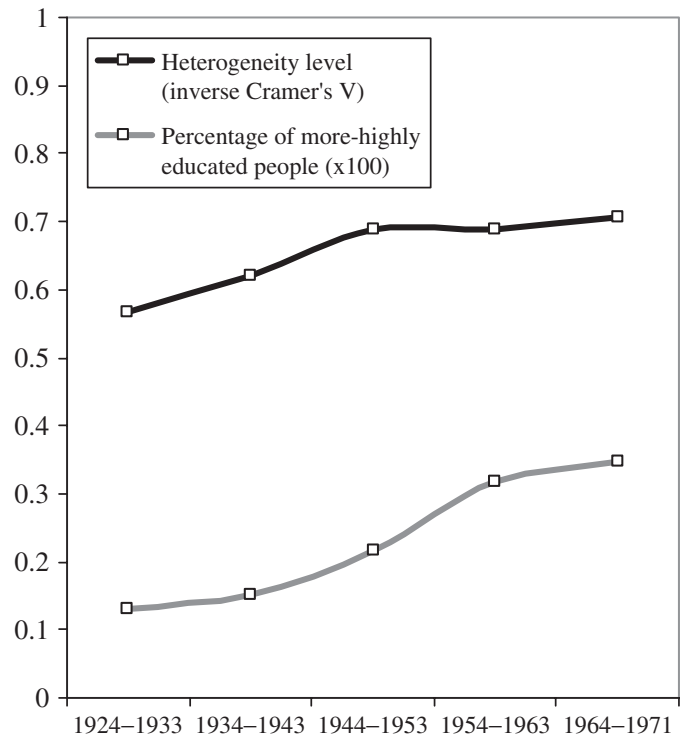

Figure 1 Educational expansion and heterogeneity in West Germany. Note: Heterogeneity is represented by the inverse Cramer's $V$ for the association between the father's Goldthorpe class and education. Source: ALLBUS 1992-2004; authors' own calculation

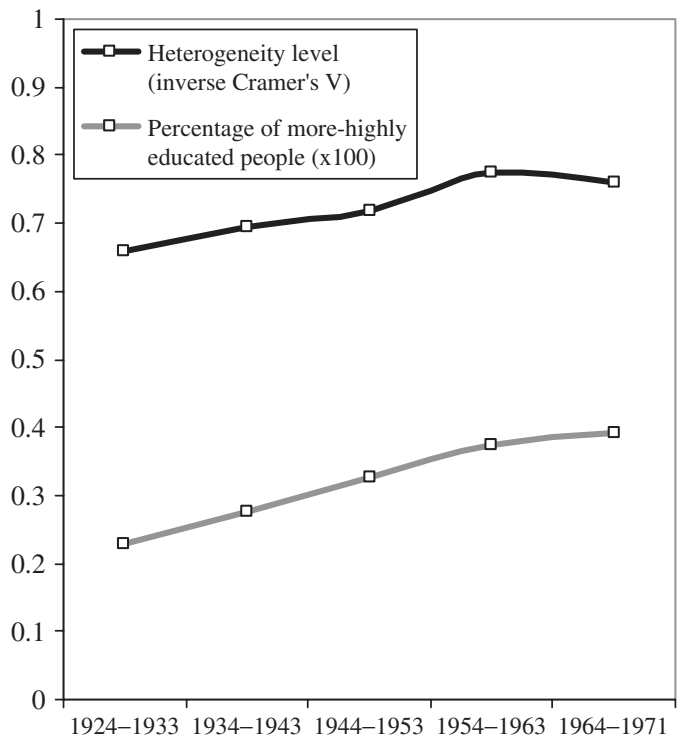

Figure 2 Educational expansion and heterogeneity in Switzerland. Note: Heterogeneity is represented by the inverse Cramer's $\vee$ for the association between the father's Goldthorpe class and education. Source: Swiss Household Panel 1999; authors' own calculation 
in the youngest cohort. The percentage of more highly educated people in Switzerland increases from about 23 per cent in the oldest cohort to nearly 39 per cent in the youngest cohort. The rise of the educational level in Switzerland is not as strong as in West Germany, because Switzerland was already characterized by a relatively high educational level at the beginning of the educational expansion in the 20th century. The link between social origin and educational level decreases slightly-and therefore heterogeneity of the pupils in intermediate and higher educational institutions increases; hence a weak trend of heterogenization can be noted. Points of stagnation of the heterogenization process seem to exist in both countries.

Visual inspections of descriptive parameters will give first impressions of the change in interest in politics in West Germany and Switzerland. As political interest was measured using different scales in both countries, the absolute parameters are comparable only to a limited extent. Therefore, it will be focussed on the course of the developments and differences between groups rather than on the political interest level in both populations. Figures 3 and 4 show the cohortspecific change in the proportion of people interested in politics over the period of analysis between 1992 and 2004.

The courses of the cohort-specific curves show the complexity of the change in political interest. Comparing the two graphs, linear trends cannot be identified-neither in Switzerland nor in West Germany. However, some cohort and period or age effects-since it cannot be ruled out whether the courses over time represent influences of age or period-may be

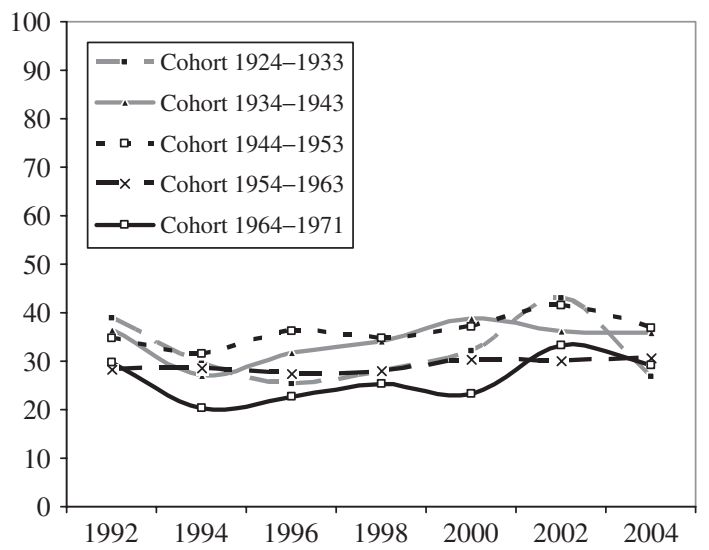

Figure 3 Cohort-specific change in political interest in West Germany, 1992-2004. Percentage of people with at least strong interest in politics in percent. Source: ALLBUS 1992-2004 recognized: In West Germany (Figure 3), interest in politics decreases between 1992 and 1994, then staying relatively constant afterwards and increasing again over the rest of the time period. A peak is found in the year 2002. This may be interpreted in terms of a rising unemployment rate and a growing dissatisfaction with the Schröder government. In Switzerland (Figure 4), a rising political interest is recognizable in particular towards the end of the period of survey. Considering the fact that discussions about an opening of the country to the rest of Europe grew with the beginning of the new century, the course of the graph indicating a rise in political interest in all cohorts seems to be plausible. Temporary and marginal peaks in the interest may be connected with votes that were related to highly discussed and controversial issues and therefore raised political interest. In both countries, cohort differences are obvious. The younger cohorts turn out to be less interested in politics than older cohorts. A negative distinction in political interest may be stated for the youngest cohort of people born between 1964 and 1971 who are less interested in politics. In West Germany, the older cohorts show the highest levels of interest throughout the time span.

In Figures 5 and 6, the three educational levels are compared regarding their interest in politics. For each cohort, the percentage of the politically interested people is indicated. First, the large gaps between the educational groups are to be noted. More highly educated people are much more interested in politics than less educated people. The political interest of people with an intermediate educational degree ranges in both countries and at all times between the interest score of

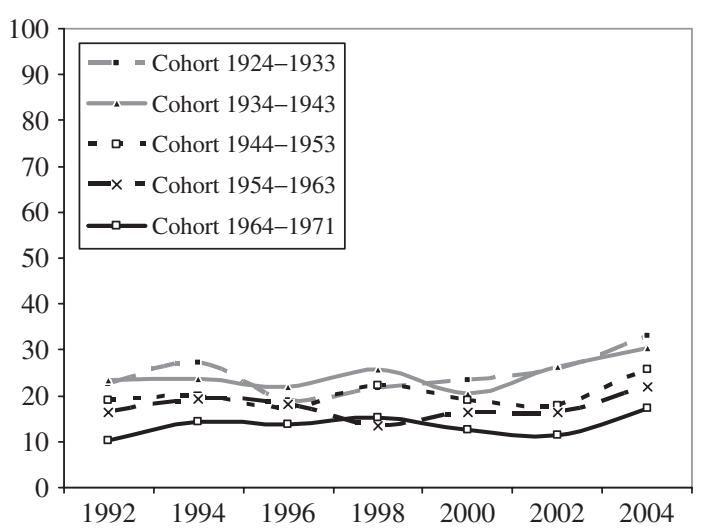

Figure 4 Cohort-specific change in political interest in Switzerland, 1992-2004. Percentage of people with very strong interest in politics in percent. Source: VOXIT 1992-2004 


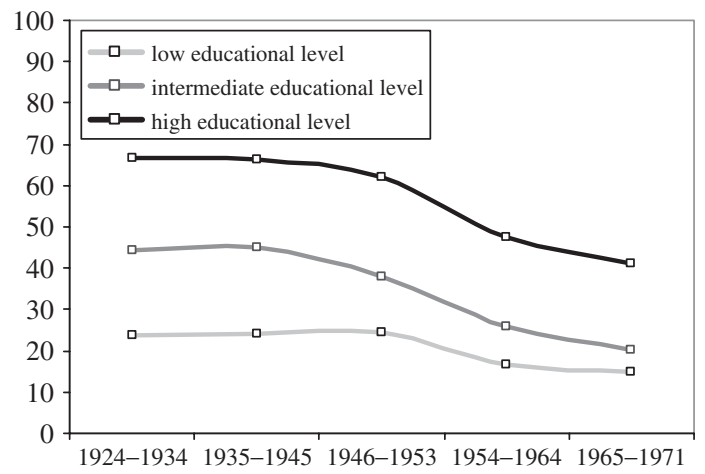

Figure 5 Interaction education $\times$ cohort, West Germany. Percentage of people with at least strong interest in politics in percent. Source: ALLBUS 1992-2004

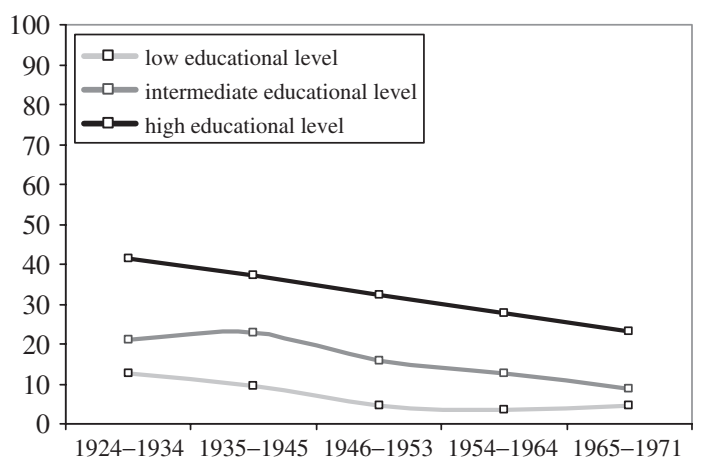

Figure 6 Interaction education $\times$ cohort, Switzerland. Percentage of people with very strong interest in politics in percent. Source: VOXIT 1992-2004

the lowest and the highest educational group. The education gap seems to be larger in West Germany, even considering the different proportions in interested people in both countries.

In West Germany, the highest and the intermediate educational groups appear to lose a larger proportion of their political interest over cohort succession than low educated people do. This would fit with the thesis of decreasing standards in intermediate and universitybound education due to the raised chances for access to further institutions of education among the working class, accompanied by a loss of distinction among the more highly educated people.

In Switzerland, an almost linear decrease in political interest over the cohorts can be identified among the highest educational group. Intermediate and low educational groups seem to lose less interest in politics over cohort succession. Therefore, also the Swiss data supports the thesis of heterogenization as part of the changing composition of school student populations.

Visual inspections of means just gave some preliminary information on the change in interest in politics during the educational expansion. These descriptive results-in particular regarding cohort differencesare not interpretable without analysing the age effect. Therefore, multivariate regression models will be estimated in a further step.

\section{Differences between West Germany and Switzerland}

As shown, whereas the mechanisms behind the change in political interest in West Germany and Switzerland may be explored by using two different data sets, the amount of political interest in the two populations is not comparable due to different measurements. To provide some evidence regarding differences between West Germany and Switzerland in some political aspects, the Eurobarometer 1999 was used to make a comparison, as here all items were measured in the same way in both subsamples. No significant differences could be found for interest in politics and information about political issues. Most interestingly, Swiss people state more often than West Germans that they have problems in understanding political debates. The difference in this aspect of internal political efficacy is statistically highly significant. The same applies to the frequency of political discussion-here Swiss people are more often engaged in such discussions.

\section{Multivariate Regression Models}

In the now following A-P-C analysis, explanatory factors will be introduced into multivariate regression models step-by-step to have a more detailed look on mechanisms behind the changes. Significant odds ratio values of above 1 indicate a positive effect of the independent variable on interest in politics; values below 1 indicate a negative effect.

Table 2 contains multivariate analysis models for the West German sample. Model 1 focuses on the education variable and the birth cohort dummies. The significant odds ratio value of 2.313 indicates that people with a high educational level have a much stronger interest in politics compared to the intermediate educational group. The low educated people have a lower political interest compared with the intermediate educational group. The youngest cohorts (born 1954-1971)—that benefited from the educational expansion-show a significant lower political interest than the people who were born before 1954 . 
Table 2 Education and interest in politics in West Germany-multivariate analyses

Logistic regression models-odds ratios

Education

High educational level

Low educational level

Reference category: intermediate educational level

Birth cohort (dummy variables)

Reference category: 1924-1933

1934-1943

1944-1953

1954-1963

1964-1971

Birth cohort (year of birth)

Interaction education $\times$ birth cohort

High educational level $\times$ birth cohort

Low educational level $\times$ birth cohort

Reference category: intermediate educational level $\times$ birth cohort

Heterogeneity in social origin of educational groups (cohort substitute)

Interaction education $\times$ heterogeneity (cohort substitute)

High educational level $\times$ heterogeneity

Low educational level $\times$ heterogeneity

Reference category: intermediate educational level $\times$ heterogeneity

Period (year of survey)

Reference category: 1992

1994

1996

1998

2000

2002

2004

Age (in years)

Age $^{2}$

Male gender

Reference category: female gender

Constant (coefficient)

$N$

Nagelkerkes $R^{2}$
Model I Model II Model III

$\begin{array}{lll}2.313^{* * *} & 2.289^{* * *} & 2.272^{* * *} \\ 0.446^{* * *} & 0.456^{* * *} & 0.444^{* * *}\end{array}$

1.006

0.933

$0.525^{* * *}$

$0.403^{* * *}$

$0.964^{* * *}$

1.005

$1.020^{* * *}$
0.335

2.549

$10.712^{* * *}$

${ }^{*} P<0.05,{ }^{* *} P<0.01,{ }^{* * *} P<0.001$.

Data Source: ALLBUS 1992-2004; authors' own calculation.

The birth cohort as a metric variable (year of birth) is introduced into Model 2. There is a slight negative effect of the year of birth on interest in politics. This contradicts the notion of an increasing political interest through cohort succession. The odds ratios and significances of the interaction effects between cohort (year of birth) and education indicate that the gap in political interest between high and intermediate educational level does not change significantly over cohort succession, whereas the intermediate educational group-and therefore also the high educational group-slightly converge to the low educated people.
This means that the groups of intermediate and more highly educated people become less distinct in their political interest from the less educated people. These results seem to support the impression the visual inspection gave.

Model 3 is the entire A-P-C model, as it contains both age and period plus homogeneity as surrogate for the cohort effect. Education remains the most important explanatory variable. As in the entire A-P-C model all three temporal effects are modelled simultaneously, the cohort substitute loses its significant influence. It may be stated that the complex A-P-C analysis reveals 
Table 3 Education and interest in politics in Switzerland-multivariate analyses

Logistic regression models-odds ratios

Education

High educational level

Low educational level

Reference category: intermediate educational level

Birth cohort (dummy variables)

Reference category: 1924-1933

1934-1943

1944-1953

1954-1963

1964-1971

Birth cohort (year of birth)

Interaction Education $\times$ Birth Cohort

High educational level $\times$ birth cohort

Low educational level $\times$ birth cohort

Reference category: intermediate educational level $\times$ birth cohort

Heterogeneity in social origin of educational groups (cohort substitute)

Interaction education $\times$ heterogeneity (cohort substitute)

High educational level $\times$ heterogeneity

Low educational level $\times$ heterogeneity

Reference category: intermediate educational level $\times$ heterogeneity

Period (year of survey)

Reference category: 1992

1994

1996

1998

2000

2002

2004

Age (in years)

Age $^{2}$

Male gender

Reference category: Female gender

Constant (coefficient)

N

Nagelkerkes $R^{2}$

\section{Model I Model II Model III}

$\begin{array}{lll}2.413^{* * *} & 2.428^{* * *} & 2.415^{* * *} \\ 0.443^{* * *} & 0.358^{* * *} & 0.415^{* * *}\end{array}$

0.939

$0.671^{* * *}$

$0.542^{* * *}$

$0.393^{* * *}$

$0.973^{* * *}$

1.006

$0.986^{*}$

0.662

1.198

0.489

${ }^{*} P<0.05,{ }^{* *} P<0.01,{ }^{* * *} P<0.001$.

Data source: VOXIT 1992-2004; authors' own calculation.

that younger cohorts have no lower political interest than older cohorts, as the heterogeneity variable shows no significant effect due to a high standard error $(B=-1.094, \quad S E=0.701)$. The interaction effects between heterogeneity and education follow the same pattern as the cohort-education interaction. The 'university-bound education $\times$ heterogeneity' effect is not significant due to high standard error $(B=0.936$, $\mathrm{SE}=0.886)$. Considering the period effect, the political interest level in the population seems to have been higher in 1992 and 2002 than in the other years of survey. The positive age effect supports the hypothesis that older people are more interested in politics than younger people are. The significant, but very week, squared age effect suggests that there is a tendency of stagnation of the increase in political interest in the later years of life. The strong gender effect indicates a gender gap in political interest: men are interested in politics more than twice as much as women.

In Table 3, the A-P-C analysis models for the Swiss population are shown. The same pattern regarding the education effect as in West Germany is indicated by the odds ratio values-low educated people show less interest in politics and more highly educated people 
show more interest in politics than the people with an intermediate educational degree do. The cohort effects are also similar to the West German results, although here the generation of the people born between 1944 and 1953 is also significantly less interested in politics than the older cohorts are. Correspondingly, the metric cohort effect in Model 2 is negative: interest in politics seems to decrease over cohort succession. The educational gap in political interest between the high and the intermediate educational level does not change significantly over cohort succession and therefore during the educational expansion, as indicated by the interaction effect 'high educational level $\times$ birth cohort'. However, the gap between low educated people and people with intermediate certificates increases-the lowest educational level gains distinction in its very low political interest over cohort succession. In the entire A-P-C model (Model 3), the effect of the cohort substitute 'heterogeneity' is not significant $(B=-0.412, \mathrm{SE}=0.459)$. Whereas education is a robust explanatory variable, this is not the case for the cohort variable in the complex model. The same applies to the interaction effects between education and heterogeneity as cohort substitute. Again, high standard errors seem to be the causes of the insignificancy of both interaction effects (low education $\times$ heterogeneity: $\quad B=-0.715, \quad \mathrm{SE}=1.004 ; \quad$ high education $\times$ heterogeneity: $B=0.181, \mathrm{SE}=0.568$ ). So there is no change in political interest in Switzerland that may be traced to cohort succession, respectively, the change in heterogeneity of the group of more highly educated people. Considering period effects, the years 1992, 1994, and 2004 are, compared to the other years of survey, characterized by a higher level in interest in politics in Switzerland. The age effect is the same as in West Germany, interest in politics increases with age. However, the squared age effect is not significant. Male gender is also positively associated with political interest as Swiss men are more interested than women.

The explained variances show that there might be other explanatory variables that have not been covered by the models yet. The higher Nagelkerkes $R^{2}$ (18.5 per cent) for the West German A-P-C model (Model 3) indicates that the societal changes during the educational expansion may have been stronger in West Germany than in Switzerland.

\section{Discussion}

Education appears to have the strongest effect on political interest-both in the West German and the
Swiss population. This finding supports the assumption made in Hypothesis 1 that more highly educated people are more cognitively mobilized and therefore show a higher interest in politics than people at the low educational level. In contradiction to ordinary analyses, results of the entire $\mathrm{A}-\mathrm{P}-\mathrm{C}$ analysis show for both populations that younger cohorts turn out to be-considering their younger age and the period of time-as much interested in politics as older cohorts were at the same age. This finding contradicts Hypothesis 2a, which postulates a rising political interest. However, results of the analyses-and in particular the cohort effect-show that assumptions of simple societal trends are insufficient. Instead, effects of age, period, and cohort need to be considered simultaneously. Another important finding is the interaction effect between cohort and education in West Germany. Here, the gap in political interest between the lowest educational level and the intermediate and high educational levels declines-as postulated in Hypothesis 2b. A possible ad hoc interpretation may be that this finding is an expression of an increasing heterogeneity of the higher educational group. However, what needs to be subject of further research is the question, if the rising heterogeneity of the student population actually led to a decreasing gap in political interest between the educational groups. In Switzerland, there is no such effect detectable in the entire A-P-C model: the changing composition of the educational groups-respectively, the process of the heterogenization of more highly educated people-does not appear to have any impact on the gap in political interest between different educational groups. Perhaps, this outcome is an impression of the higher consensus in the Swiss population towards politics-that may also be indicated in the lower education effect. Period effects (Hypothesis 3) could be figured out for both West Germany and Switzerland for 1992 and, partly, for the beginning of the 21st century. Evidences provide clear support for the assumed age effect (Hypothesis 4); political interest increases with age. The effect of the control variable 'gender' refers to the expected gender differences; men are more interested in politics than women.

A theoretical issue for discussion is the question if the education effect is just an effect of cognitive mobilization or if there is also an effect regarding the content of education. An argument could be that higher schools are socialization agents for values of participation, whereas in lower schools such values are not that much promoted. Another issue that may be raised is the measurement of interest in politics with one item. Although no other items to measure interest 
in politics (e.g. politics as entertainment, as oversight of government, and of stake in political outcomes; as suggested by Horner, 2005) were available, our analyses-that may be interpreted as external validation-have shown a substantial interestbehaviour link.

There are several methodological limitations to be addressed. First, it must be again pointed to the different educational systems and the different measurements. For the longitudinal analyses, data was reduced to a binary education variable and a binary political interest variable. Furthermore, the political interest variable of both populations is based on different surveys due to the lack of appropriate alternatives: Swiss data was gathered after votes, whereas West German data is based on surveys after elections. By considering only the 'very strong interested' Swiss people as politically interested citizens, this bias can be controlled to a large extent. Nevertheless, the variables on political interest are only partly comparable. As already mentioned, this study could not give answers to the question, which educational system does produce a higher amount of more highly educated people and which system is characterized by a higher political interest. The focus lies on analysing the social mechanisms-in particular, the link between educational level, cohort, period, and age on political interest. A last concern is the rather short time period from 1992 to 2004. Longitudinal data sets that cover longer periods are needed to separate age, period, and cohort effects even more adequately.

What did become clear during the analyses is that although Switzerland and West Germany have two different political systems, the mechanisms behind the change in political interest and in particular the link between educational expansion and the political mobilization are similar in both countries.

\section{Notes}

1. This finding mainly applies to the association between social class and education-as Shavit et al. (2007) point out, other variables of origin like the parental education may be more resistant to temporal change.

2. According to Boehnke et al. (2007), Zeitgeist is defined as the modal value climate of a society.

3. Evidence from the World Values Survey-here political interest was measured on the same fourstep scale in West Germany and Switzerlandsupports our finding and therefore the measurement strategy. In 1990, 69.4 per cent were some or very interested in politics in West Germany, in Switzerland only 65.7 per cent, in 1995/1996 77.9 per cent were some or very interested in West Germany and only 40.4 per cent in Switzerland. Although the WVS data may be problematic regarding biases and data problems, these evidences are also supported by the findings regarding young people from TorneyPurta et al. (2001) who attest Swiss adolescents a below-average interest in politics and a belowaverage political knowledge. Whereas the trust in the political system is very high in Switzerland, the political interest is very low. Interest in politics among adolescents in Germany is much higher than in Switzerland (Maiello, 2003).

4. Due to the inclusion of certificates that are formally below the maturity level but in fact belong to the higher certificates, the educational level in Switzerland is-from our perspective and according to the data-higher than in West Germany.

5. Both in the German ALLBUS and the SHP data sets, the original 11-class version is used to categorize fathers' class. For an optimal Cramer's V estimation-both variables should have a similar number of categories-we collapsed the 11-class version into a four-class version of this schema (Breen, 2005, p. 41) that differentiates between 'service class' (upper and lower service class), 'intermediate class' (higher grade routine non-manual employees, lower-grade technicians, and supervisors of manual workers), 'petty bourgeoisie' (small proprietors with and without employers, farmers, and other selfemployed workers), and 'manual class' (lower grade routine non-manual employees, skilled and semi- or unskilled manual workers).

6. The category 'high educational level' consists of people with at least full general or vocational maturity certificates. In Switzerland, some certificates that are no formal maturity certificates, but are on the same level and are a regular starting point for further education, are included in this group.

\section{References}

Baumert, J. (1991). Langfristige Auswirkungen der Bildungsexpansion. Unterrichtswissenschaft, 19, 333-349. 
Baumert, J., Artelt, C., Klieme, E., Neubrand, M. et al. (Eds) (2003). Pisa 2000 - Ein differenzierter Blick auf die Länder der Bundesrepublik Deutschland. Opladen: Leske + Budrich.

Becker, R. (2003). Educational expansion and persistent inequalities of education. European Sociological Review, 19, 1-24.

Becker, R. (2004). Voter turnouts in East and West Germany. German Politics, 13, 1-19.

Boehnke, K., Hadjar, A. and Baier, D. (2007). Parentchild value similarity: the role of Zeitgeist. Journal of Marriage and Family, 69, 778-792.

Bourdieu, P. (1984). Distinction: A Social Critique of the Judgement of Taste. Cambridge, MA: Harvard University Press.

Brauns, H. and Steinmann, S. (1999). Educational reform in France, West-Germany and the United Kingdom: updating the CASMIN educational classification. ZUMA-Nachrichten, 44, 7-44.

Breen, R. (2005). Foundations of neo-Weberian class analysis. In Wright, E. O. (Ed.), Approaches to Class Analysis. Cambridge: Cambridge University Press, pp. 31-50.

Breckler, St. J. (1984). Empirical validation of affect, behaviour, and cognition as distinct components of attitude. Journal of Personality and Social Psychology, 47, 1191-1205.

Buchmann, M., Charles, M. and Sacchi, S. (1993). The lifelong shadow. Social origins and educational opportunity in Switzerland. In Shavit, Y. and Blossfeld, H.-P. (Eds), Persistent Inequality. Boulder/San Francisco/Oxford: Westview Press, pp. 177-192.

Bürklin, W., Klein, M. and Ruß, A. (1994). Dimensionen des Wertewandels. Politische Vierteljahresschrift, 35, 579-606.

Cumming, E. M. and Henry, W. E. (1961). Growing Old. New York: Basic Books.

Dahrendorf, R. (1965). Bildung ist Bürgerrecht. Hamburg: Nannen.

Dalton, R. J. (1984). Cognitive mobilization and partisan dealignment in advanced industrial democracies. The Journal of Politics, 46, 264-284.

Easton, D. (1975). A re-assessment of the concept of political support. British Journal of Political Science, 5, 435-457.

Ebbinghaus, B. (2005). When less is more: selection problems in large- $\mathrm{N}$ and small-N cross-national comparisons. International Sociology, 20, 133-152.

Erikson, R., Goldthorpe, J. H. and Portocarero, L. (1979). Intergenerational class mobility in three Western European societies: England, France and Sweden. British Journal of Sociology, 30, 341-415.
Freitag, M. (1996). Wahlbeteiligung in westlichen Demokratien. Swiss Political Science Review, 2, $1-134$.

Gabriel, O. W. and van Deth, J. W. (1995). Political interest. In van Deth, J. W. and Scarbrough, E. (Eds), The Impact of Values. Oxford: Oxford University Press, pp. 390-411.

Glenn, N. D. (2005). Cohort Analysis. Thousand Oaks: Sage.

Glenn, N. D. and Grimes, M. (1968). Aging, voting, and political interest. American Sociological Review, 33, 563-575.

Hadjar, A. and Becker, R. (2006a). Politisches Interesse und politische Partizipation. In Hadjar, A. and Becker, R. (Eds), Die Bildungsexpansion. Wiesbaden: VS Verlag für Sozialwissenschaften, pp. 179-204.

Hadjar, A. and Becker, R. (2006b). Bildungsexpansion und Wandel des politischen Interesses in Westdeutschland zwischen 1980 und 2002. Politische Vierteljahresschrift, 47, 12-34.

Hadjar, A. and Becker, R. (2007). Unkonventionelle politische Partizipation im Zeitverlauf. Kölner Zeitschrift für Soziologie und Sozialpsychologie, 59, 410-439.

Hagenaars, J. A. (1990). Categorical Longitudinal Data. Log-linear Panel, Trend, and Cohort Analysis. Newbury Park, CA: Sage.

Hess, R. D. and Torney, J. V. (1970). The Development of Political Attitudes in Children, 2nd edition. Chicago, IL: Aldine.

Hoffmann-Lange, U. (1993). Jugend und politik. In Andersen, U. and Woyke, W. (Eds), Handwörterbuch des politischen Systems der Bundesrepublik Deutschland. 4. Auflage. Bonn: Bundeszentrale für politische Bildung, pp. 247-251.

Horner, D. A. (2005). Expanding the Measurement of Political Interest. Paper presented at the annual meeting of the Midwest Political Science Association, Chicago: IL, available from: <http:// www.allacademic.com/meta/p85094_index.html> [accessed 5 October 2006].

Inglehart, R. (1977). The Silent Revolution. Princeton: Princeton University Press.

Inglehart, R. (1990). Culture Shift in Advanced Industrial Society. Princeton: Princeton University Press.

Klages, H. (1984). Wertorientierungen im Wandel. Frankfurt am Main/New York: Campus.

Klingemann, H.-D. and Fuchs, D. (Eds) (1995). Citizens and the State. Oxford: Oxford University Press.

Lazarsfeld, P., Berelson, B. and Gaudet, H. (1948). The People's Choice. New York: Duell, Sloan, \& Pearce. 
Lind, G. (1985). The theory of moral-cognitive development. In Lind, G., Hartmann, H. A. and Wakenhut, R. (Eds), Moral Development and the Social Environment. Chicago: Precedent, pp. 21-53.

Lind, G. (1988). Moral und Bildung. Zur Kritik von Kohlbergs Theorie der moralisch-kognitiven Entwicklung. Heidelberg: Asanger.

Mannheim, K. (1928). Das Problem der Generation. Kölner Vierteljahresschrift für Soziologie, 7, 157-185/ 309-330.

Maiello, C. (2003). Politisches engagement und politische Aktivität. In Oser, F. and Biedermann, H. (Eds), Jugend ohne Politik. Zürich: Rügger Verlag, pp. 129-154.

Metje, M. (1994). Wählerschaft und Sozialstruktur im Generationenwechsel. Wiesbaden: Westdeutscher Verlag.

Müller, W. and Shavit, Y. (1998). The institutional embeddedness of the stratification process. In Müller, W. and Shavit, Y. (Eds), From School to Work: A Comparative Study of Educational Qualifications and Occupational Destinations. Oxford: Oxford University Press, pp. 1-148.

Müller, W. (1998). Erwartete und unerwartete Folgen der Bildungsexpansion. In Friedrichs, J., Lepsius, R. and Mayer, K.-U. (Eds), Die Diagnosefähigkeit der Soziologie. Opladen: Westdeutscher Verlag, pp. 81-112.

Panchaud, G. (1967). School reform in Switzerland. Comparative Education Review, 11 (Ten Years of European Education Reform, 1956-1966), 374-386.

Rieger, A. (2001). Bildungsexpansion und ungleiche Bildungspartizipation am Beispiel der Mittelschulen im Kanton Zürich, 1830-1980. Schweizerische Zeitschrift für Bildungswissenschaften, 23, 41-72.

Schelsky, H. (1956). Soziologische Bemerkungen zur Rolle der Schule in unserer Gesellschaftsverfassung. In Schelsky, H. (Ed.), Schule und Erziehung in der industriellen Gesellschaft. Würzburg: WerkbundVerlag, pp. 9-50.
Shavit, Y., Yaish, M. and Eyal, B.-H. (2007). The persistence of persistent inequality. In Scherer, S., Pollak, R., Otte, G. and Gangl, M. (Eds), Origin to Destination. Trends and Mechanisms in Social Stratification Research. Frankfurt am Main: Campus, pp. 37-57.

Solga, H. (2002). 'Stigmatization by negative selection': explaining less-educated persons' decreasing employment opportunities. European Sociological Review, 18, 159-178.

Tuma, N. B. and Hannan, M. T. (1984). Social Dynamics: Models and Methods. Orlando: Academic Press.

van Deth, J. (1990). Interest in politics. In Jennings, M.K. and van Deth, J. (Eds), Continuities in Political Action. Berlin: de Gruyter, pp. 275-312.

Verba, S. and Nie, N.H. (1972). Participation in America. Political Democracy and Social Equality. New York, NY: Harper Row.

Vetter, A. (2000). Frischer Wind in einer alten Beziehung? Political efficacy und die Bundestagswahl 1998. In Falter, J. W., Gabriel, O. W. and Rattinger, H. (Eds), Wirklich ein Volk? Die politischen Orientierungen von Ost- und Westdeutschen im Vergleich. Opladen: Westdeutscher Verlag, pp. 79-109.

\section{Authors' Addressess}

Andreas Hadjar (to whom correspondence should be addressed), Department of Sociology of Education, University of Bern, CH-3012 Bern, Switzerland. Tel.: +41 31631 5356; Fax: +41 316315352. Email: andreas.hadjar@edu.unibe.ch

Florian Schlapbach, Department of Sociology of Education, University of Bern, CH-3012 Bern, Switzerland.

Email: florian.schlapbach@edu.unibe.ch 